\title{
Advanced Hemodynamic and Cardiopulmonary Ultrasound for Critically III Patients in the Emergency Department
}

Jarrod M. Mosier, MD; Jennifer Martin, MD; Phillip Andrus, MD; Michelle Clinton, MD; Vishal Demla, MD; Vi Am Dinh, MD; Turandot Saul, MD; Christopher K. Schott, MD, MS, RDMS; Vivek Tayal, MD

\section{Focused echocardiography, advanced hemodynamic, and cardiopulmonary point-of-care ultrasound studies provide time-sensitive evaluation of critically ill patients, guiding and facilitating earlier implementation of life-preserving treatment and supportive therapies.}

O ritically ill patients presenting to the ED represent the most timesensitive patient encounter for the emergency physician (EP), as delays in restoring physiological homeostasis increase the risks of organ dysfunction and death. Management and treatment strategies in critically ill patients have evolved from the routine use of invasive catheters and radiography for cardiopulmonary evaluation to a variety of noninvasive devices and pathways. The widespread adoption of point-of-care ultrasound (POCUS) in EDs provides the opportunity to rapidly obtain invaluable information about the diagnosis and etiology to guide resuscita-

Dr Mosier is an associate professor of emergency medicine, department of emergency medicine; an associate professor of medicine, department of medicine, section of pulmonary, critical care, allergy and sleep; and the associate medical director, Adult ECMO Program, all at the University of Arizona, Tucson. Dr Martin is an assistant professor, department of emergency medicine, St. Francis Hospital and Medical Center, University of Connecticut, Hartford. Dr Andrus is an associate professor, division of emergency ultrasound, department of emergency medicine, Icahn School of Medicine at Mount Sinai, New York, New York. Dr Clinton is an assistant professor, department of emergency medicine, Carilion Roanoke Memorial Hospital, Virginia Tech Carilion; associate ultrasound director, Carilion Roanoke Memorial Hospital; ultrasound director, Carilion New River Valley Hospital, Roanoke, Virginia. Dr Demla is an assistant professor, department of emergency medicine and division of critical care medicine, The University of Texas Health Science Center at Houston. Dr Dinh is an associate professor of emergency medicine and internal medicine, division of pulmonary and critical care, Loma Linda University Medical Center, California. Dr Saul is an associate professor, division of emergency ultrasound, department of emergency medicine, Icahn School of medicine at Mount Sinai, New York, New York. Dr Schott is an assistant professor, departments of critical care and emergency medicine; director of critical care ultrasonography; VA Pittsburgh Healthcare system and the University of Pittsburgh/UPMC, Pennsylvania. Dr Tayal is a professor, department of emergency medicine; and director, division of emergency ultrasound, Carolinas Medical Center, Charlotte, North Carolina.

Authors' Disclosure Statement: The authors report no actual or potential conflict of interest in relation to this article.

DOI: 10.12788/emed.2018.0078 


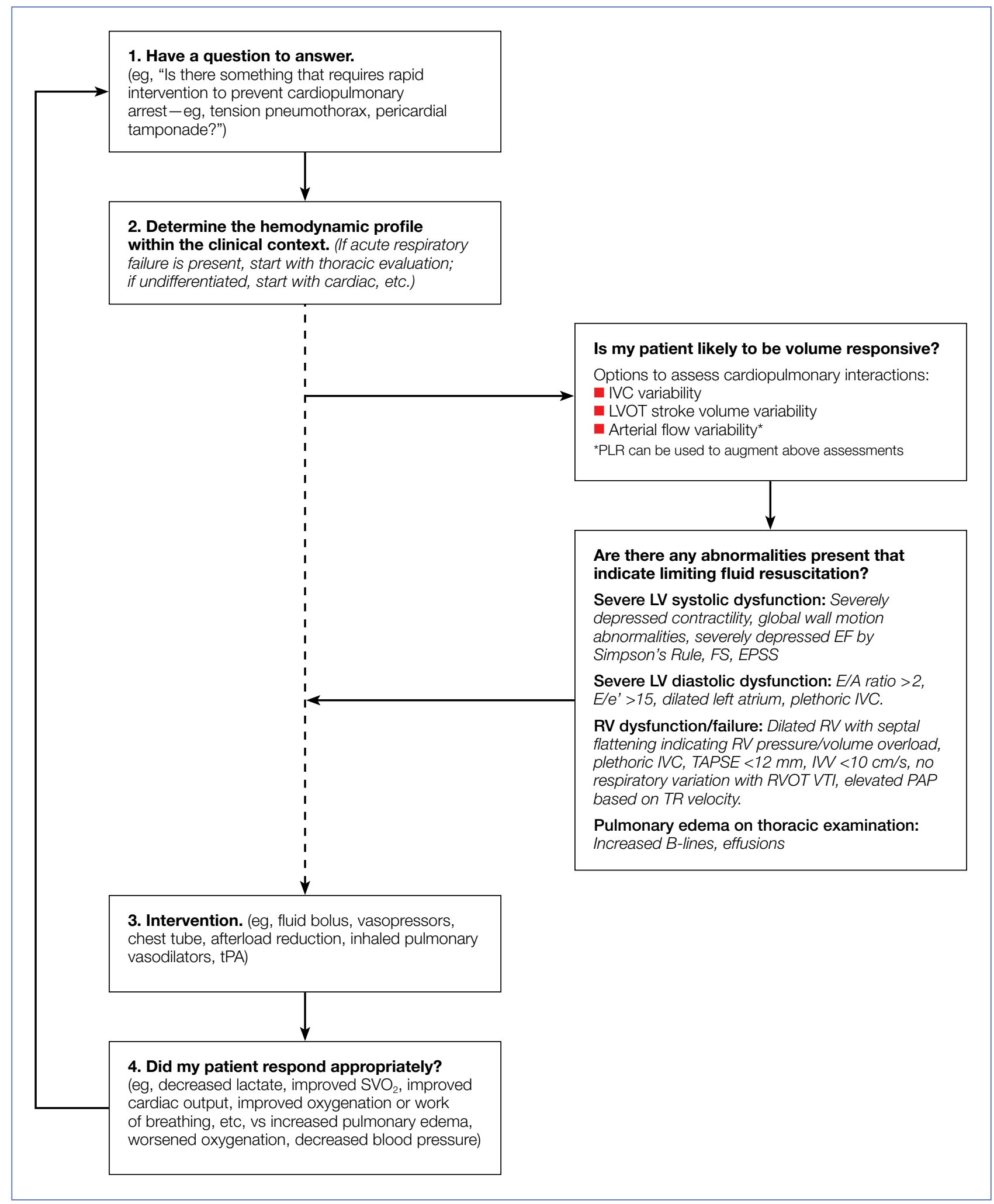

Figure 1. Suggested workflow outlining a step-wise approach to evaluating the critically ill patient.

Abbreviations: e', early diastolic mitral annulus velocity; E/A, E-wave/A-wave ratio; EF, ejection fraction; EPSS, E-point septal separation; FS, fractional shortening; IVC, inferior vena cava; IW, isovolumetric contraction velocity; LV, left ventricle/ventricular; LVOT, left ventricular outflow tract; PAP, pulmonary artery pressure; PLR, passive leg raise; RV, right ventricle/ventricular; RVOT, right ventricular outflow tract; $\mathrm{SVO}_{2}$, mixed venous oxygen saturation; TAPSE, tricuspid annular plane systolic excursion; tPA, tissue plasminogen activator; TR, tricuspid regurgitation; VTI, velocity time integral. 
tion in critically ill patients-particularly those in shock and acute dyspnea.

Over the last two decades, EPs and critical care physicians have employed POCUS to assist in identifying emergent reversible causes of shock and cardiac arrest, including cardiac tamponade, massive pulmonary embolism (PE), and hemoperitoneum. Recent advances in hemodynamic and cardiopulmonary POCUS allow for a nuanced approach to hemodynamic evaluation. ${ }^{1}$ In addition, the use of ultrasound "first" in the critical care setting may reduce the dependence on radiographic-based management, catheter-based protocols, and the need for invasive procedures.

Bedside cardiopulmonary ultrasound to evaluate the hemodynamic status of hypotensive patients can help determine the etiology of shock, provide evidence of fluid-volume responsiveness, visualize hemodynamic abnormalities that would alter fluid resuscitation strategies, and assess patient response to an intervention. The use of ultrasound can also identify the etiology of acute respiratory failureproviding the opportunity to initiate the appropriate interventions prior to patient decompensation. Findings such as pneumothorax or pleural effusion may require immediate procedural intervention, while other findings may only require noninvasive positive pressure ventilation and diuresis.

The tools to implement these concepts include basic POCUS education common to emergency medicine and critical care (American College of Emergency Physicians Guidelines and American College of Chest Physicians/Society of Critical Care Medicine guidelines); ultrasound machines with phased array, linear, and curvilinear probes; and ultrasonographic instrumentation such as M-Mode, color Doppler, and spectral Doppler. An understanding of common Doppler imaging techniques optimizes the examination, and the use of presets common to cardiac packages may further assist the provider with adoption.
When evaluating critically ill patients, we recommend the following step-wise approach:

- Identify a clinical question to be answered prior to doing the examination;

- Determine the hemodynamic profile of the patient to guide therapeutic maneuvers; and

- Monitor the response to any therapeutic maneuver and adjust accordingly. (In these complicated patients, repeat examinations are invaluable, as the hemodynamic profile can change rapidly.)

Figure 1 summarizes these recommendations into a workflow that the EP may find useful for applying these concepts. In this paper, we review the recent advances in hemodynamic and cardiopulmonary POCUS to optimize the care of the critically ill patient.

\section{Thoracic Assessment}

Emergency physicians are increasingly utilizing POCUS to rapidly evaluate the thoracic cavity in critically ill patients. This modality is an appealing alternative to formal chest radiography because of the ease of rapid image acquisition, lack of ionizing radiation, and the ability to repeat the examination in real-time.

When critically ill patients present in respiratory distress, POCUS allows the EP to rapidly diagnose potential etiologies, such as pleural effusion, pneumothorax, or pulmonary edema, and employ emergent intervention, which can greatly alter the patient's clinical course. Additionally, the rapid diagnosis of consolidation permits earlier appropriate management of sepsis and respiratory failure when the clinical setting is consistent with pneumonia.

In many cases, ultrasound has been shown to be superior to traditional chest radiography to assess critically ill patients. ${ }^{2-8}$ Although there are several protocols that utilize thoracic ultrasound in evaluating the critical patient, this review focuses solely on the components of thoracic ultrasound, rather than specific protocols. 

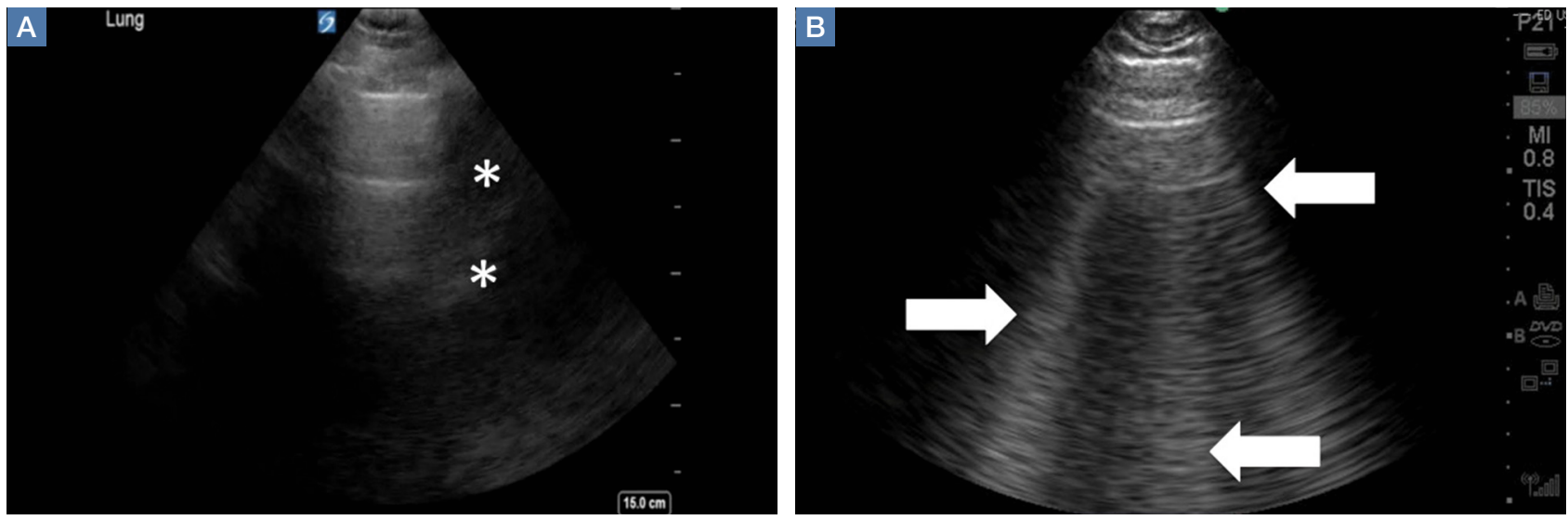

Figure 2. Ultrasound images demonstrating (A) normal-appearing (A-profile) lungs with visible subcutaneous tissue, ribs, pleural line, and artifact A-lines (white asterisks) produced by air-filled alveoli attenuating sound waves; and (B) the appearance of B-lines (white arrows) replacing the previous A-line reverberations in alveoli filled with fluid.

\section{Pneumothorax}

Ultrasound imaging with a high-frequency probe is highly sensitive and specific in assessing for pneumothorax in a supine patient. ${ }^{9}$ In the normal lung, the visceral and parietal pleura are visualized as sliding with each breath. In this examination, the transducer is placed on the chest wall to visualize two ribs and the pleura between them (Figures 2a and 2b). Evaluation at several points along the anterior chest wall improves the sensitivity of the examination. Typically, scanning begins at the level of the second intercostal space at the midclavicular line and extends laterally through the midaxillary line.

When lung sliding is present, the appearance in M-mode is that of the "seashore" or "sandy beach." The hyperechoic white pleura is seen as moving with the respiratory cycle. Additionally, lung artifacts such as A-lines, horizontal reverberation artifacts; and B-lines (also referred to as "comettails"), vertical lines arising from distended subpleural alveoli, will be seen in a normal lung. If pneumothorax is present, no sliding or comet-tail artifacts will be present at the pleural surface. Although A-lines may also be absent in pneumothorax, studies have shown that the absence of lung sliding and the presence of A-lines are associated with increased specificity ( $94 \%$ vs $78 \%$ with absent lung sliding alone) for diagnosing occult pneumothorax. ${ }^{9}$ This is referred to as the "stratosphere" or "barcode" sign when visualized in M-mode (Figures 3a and $\mathbf{3 b}$ ).

While the lack of pleural sliding is highly sensitive for pneumothorax, the clinician must place this finding within the clinical context of the patient. For example, an intubated patient may not have left-sided sliding in the case of a right main-stem intubation. Moreover, patients who have an underlying obstructive lung disease (eg, chronic obstructive pulmonary disease [COPD]) and/or emphysema may present a more challenging examination because pleural sliding is often absent, especially in the apical segments, and can mimic pneumothorax in these patients. ${ }^{10}$

In addition to pleural sliding, presence or absence of a lung pulse also assists in assessing patients for pneumothorax. The detection of a lung pulse on M-mode ultrasound indicates subtle cardiac pulsation at the periphery of the lung; this finding only appears in the nonventilated lung in the absence of a pneumothorax. The presence of lung pulse is therefore useful in distinguishing other causes of nonventilated lung from pneumothorax. ${ }^{11}$

\section{Pleural Fluid}

The low-frequency curvilinear or phased array probes are used to assess for pleural fluid. In this study, the clinician fans the probe cephalad from Morison's pouch on the patient's right side, or from the 

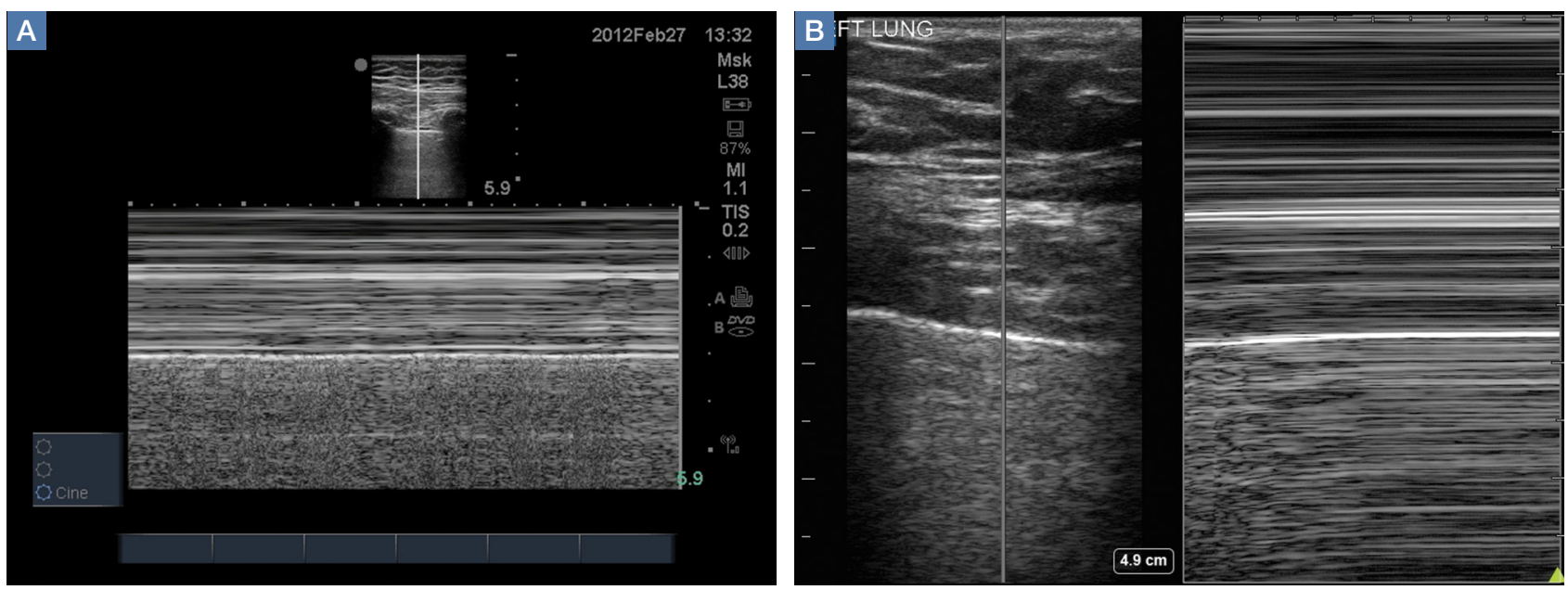

Figure 3. M-mode ultrasound images demonstrating $(\mathbf{A})$ the appearance of lung sliding, referred to as the "seashore" or "sandy beach" signs; and (B) the absence of lung sliding, referred to as the "bar code" or "stratosphere" sign.

splenorenal recess on the left side, to visualize the bright, hyperechoic diaphragm. If pleural fluid is present, there will be loss of the mirroring artifact, and the fluid will appear as an anechoic collection cephalad to the diaphragm. In addition, when fluid is present, the normal lung may be visualized moving within the effusion, evoking a quad or sinusoid sign with M-mode imaging. ${ }^{12,13}$ In the setting of complicated parapneumonic effusion, the echogenicity may be mixed or difficult to detect.

Visualization of the thoracic spine above the diaphragm may serve as a surrogate marker for the presence of fluid. Typically, the thoracic spine is not visualized on ultrasound due to the scatter caused by the air-filled lungs. However, when fluid is present, the ultrasound waves are not scattered, permitting visualization of the thoracic spine (Figure 4a) ${ }^{14}$

Ultrasound has been shown to be superior to routine chest radiograph for the identification of small pleural effusions. ${ }^{7}$ Given that both critically ill medical and injured patients can present with pleural fluid, the use of POCUS to rapidly determine the presence or absence of fluid is an adjunct in the evaluation of these patients.

\section{Interstitial Fluid}

Evaluation of the thoracic cavity for interstitial fluid in the setting of acute pulmonary edema, acute respiratory distress syndrome (ARDS), or interstitial pneumonia is best accomplished using either the curvilinear low-frequency probe or the phased array probe. The visualization of vertically oriented B-lines in the upper lung fields is very sensitive for interstitial fluid or edema of the interlobular septa (Figures 2a and 2b). ${ }^{13,15}$ In this study, B-lines originate at the pleural line, move with the pleura, and extend off the bottom of the monitor without obliteration (in contrast to A-lines). An isolated B-line may be physiological; however, the presence of several B-lines is consistent with an interstitial pathology. On imaging, the presence of three or more B-lines in a single rib space with a convex probe, or more than six B-lines when utilizing the curvilinear, is considered pathological and referred to as "lung rockets." B-lines may be focal or diffuse, as seen respectively in cases of pneumonia or acute pulmonary edema. ${ }^{16}$

\section{Pulmonary Assessment for Fluid Resuscitation}

\section{Fluid Resuscitation}

Lung ultrasound studies have been proposed as a means of determining adequate fluid resuscitation and preventing complications associated with excessive fluid. The appearance of diffuse B-lines of acute interstitial syndrome on lung ultrasound can uncover the first signs of extravascular 

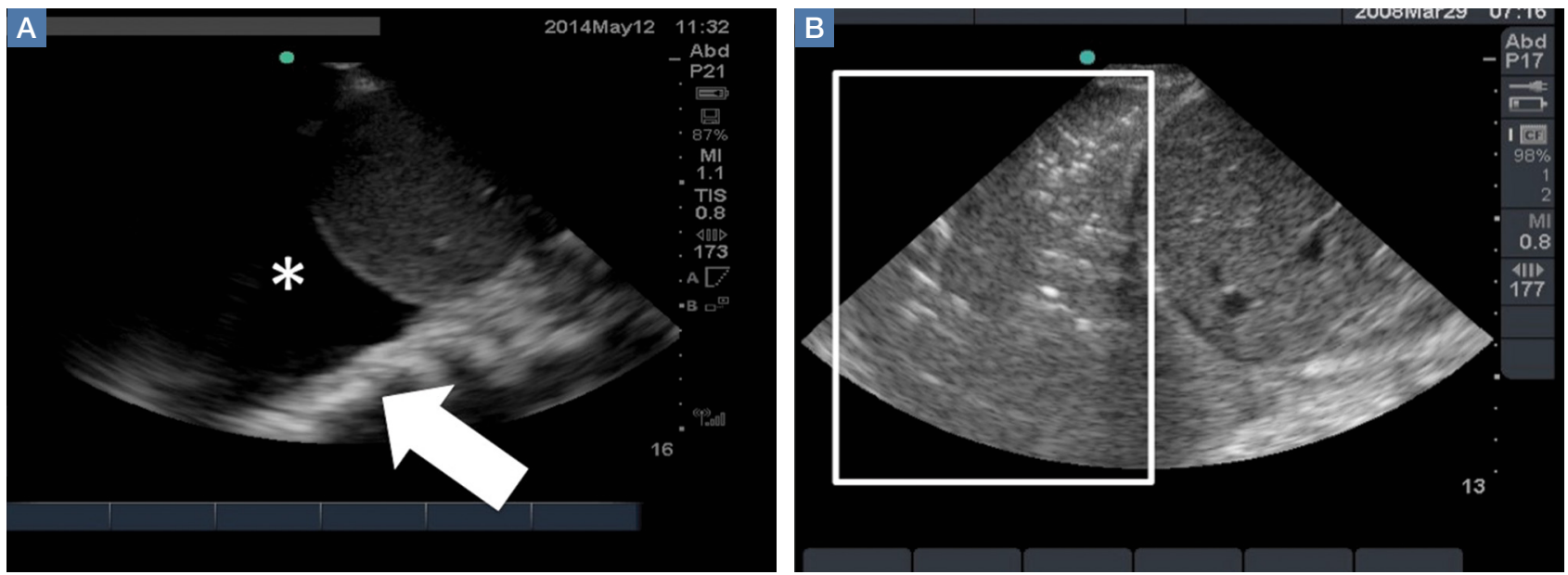

Figure 4. Ultrasound images demonstrating (A) pleural effusions (white asterisk) seen above the diaphragm, which are hypoechoic, providing easy visualization of the thoracic spine (white arrow), referred to as the "spine sign"; and (B) the presence of dense consolidations of the lung, as seen in pneumonia or acute respiratory distress syndrome. Hepatization (white box) can be seen where the lung parenchyma begins to appear similar to that of the liver, with air bronchograms becoming more visible from collapse of surrounding parenchyma from edema, inflammation, fluid, and atelectasis.

lung water and prevent pulmonary alveolar edema and associated morbidity and mortality. ${ }^{17}$ The appearance of an A-line predominance throughout the lung does not predict fluid responsiveness, but rather potential fluid tolerance.

A benefit of lung ultrasound is that it provides information more rapidly than many of the dynamic measures of fluid responsiveness and cardiac output variability. In addition, lung ultrasound studies are much more easily reproduced than repeating a velocity time integral (VTI) measurements.

\section{Lichtenstein's FALLS Protocol}

Lichtenstein's FALLS (Fluid Administration Limited by Lung Sonography) protocol provides an approach to performing lung ultrasound on patients presenting in shock. ${ }^{12}$ In this approach, lung ultrasound studies are performed after echocardiography to evaluate the patient for causes of obstructive shock. The predominance of B-lines on lung ultrasound suggests cardiogenic shock and, by definition, fluid intolerance. The predominance of A-lines on ultrasound may be present in patients in hypovolemic or septic shock.

In hypovolemic shock, continued fluid boluses will improve hemodynamics with preserved A-line predominance. In septic shock, B-lines will begin to appear, suggesting that other means of improving forward flow should be initiated.

\section{Consolidation}

Chest radiography is known to have variable test characteristics for the detection of pneumonia. Consolidation may not be detected in profoundly immunocompromised or dehydrated patients. Additionally, in critically ill patients, it is often challenging to obtain a posteroanterior and lateral chest X-ray, given the patient's hemodynamic status and stability for transport, and a single portable anteroposterior film will often miss retrocardiac infiltrates. In both of these clinical settings, POCUS can provide a rapid diagnosis, expediting the care of these septic patients.

In the presence of a dense consolidation, there may be hepatization of the lung parenchyma (Figure 4b). Additionally, hyperechoic air bronchograms are often visualized. Pneumonia is often associated with pleural effusion and localized B-lines. Using lung ultrasound, rapid bedside detection of these pulmonary findings in clinical presentations suggestive of pneumonia can accelerate appropriate antibiotic and respiratory supportive treatment. 


\section{Left Ventricular Systolic Assessment}

Critically ill patients commonly present with a mixed shock picture, and it is rare for a patient to have solely cardiogenic shock, hemorrhagic shock, etc. Rather, a patient who presents in septic shock may have an underlying cardiomyopathy for which she or he is being treated with a beta-blocker.

Cardiomyopathy associated with sepsis is common ${ }^{18}$ and, at least in the case of diastolic dysfunction, it is underdiagnosed and associated with a higher mortality rate..$^{19}$ It is therefore essential that the EP evaluate left ventricular (LV) systolic function rapidly and reliably-particularly in critically ill patients whose disease process may be undifferentiated and whose hemodynamic status is unclear. ${ }^{20-22}$ Bedside echocardiography by the EP is invaluable in identifying the LV contribution to the hemodynamic profile and tailoring resuscitation to optimize patient outcomes.

Although gross visual assessment is the most widely used method by which EPs estimate LV systolic function, this strategy is subjective, operator-dependent, and requires at least two quality views to understand the heart's three-dimensional movement. However, when faced with a rapid diagnostic dilemma, a global visual estimate of the overall contractility (hyperdynamic, normal, depressed, severely depressed) may be more useful than estimating the ejection fraction (EF), especially when the patient's baseline EF is unknown.

\section{Regional Wall-Motion Abnormalities}

Regional wall-motion abnormalities can be evaluated by considering and correlating the coronary artery distributions with the electrocardiographic findings and the clinical scenario (Figure 5). Each region can be assessed for degree of movement of the myocardium toward the center of the LV during systole, or abnormal thickening of the ventricular walls. Although the
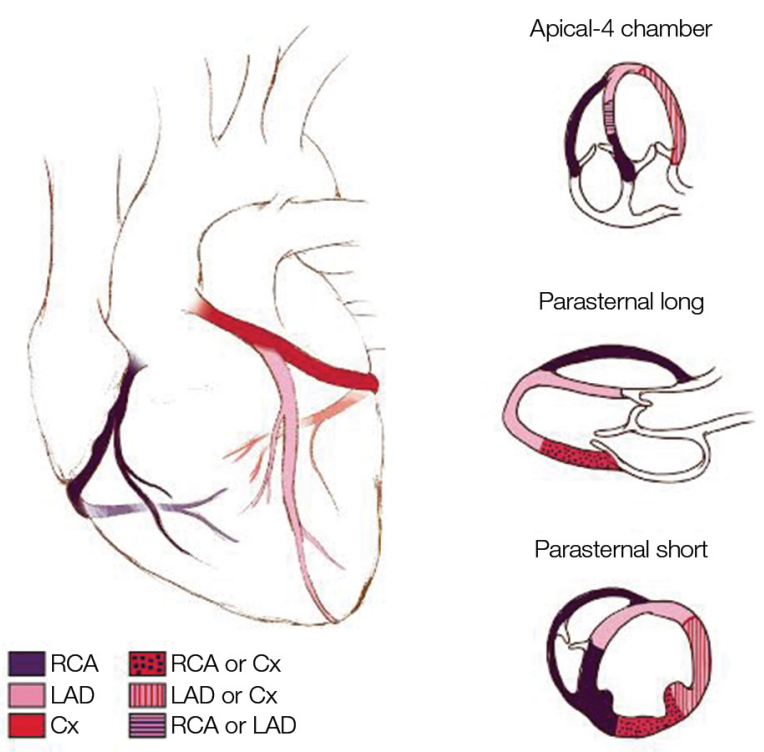

Parasternal short

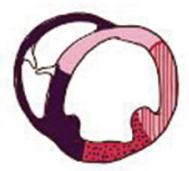

Figure 5. Anatomy of the coronary artery and its distribution as it relates to standard echocardiographic views.

Abbreviations: Cx; circumflex artery; LAD, left anterior descending; RCA, right coronary artery.

American Heart Association uses a 17-segment model for this assessment, this level of detail may not be necessary for a POCUS evaluation. ${ }^{23}$

\section{Simpson's Rule}

Although no one parameter can quantitatively assess LV function, the $\mathrm{EF}$ is the one most commonly used. The Simpson's Rule or the "method of disks" estimates EF by changes in calculated ventricular volumes. The endocardial border is outlined in enddiastole and end-systole (ES) in both the apical four- (AP4) and two-chamber views. The cardiac package on the ultrasound system can divide the selected area into a series of disks, calculate the volume of each disk, and then add these figures to estimate the ventricular volume (Figure 6a). Limitations of this study include potentially difficult visualization of the endocardial border, and the length of time to conduct this study.

\section{Fractional Shortening}

M-mode ultrasound can be used in several ways to estimate LV EF. Fractional shortening (FS) estimates the size reduction of the LV during systole. In the 

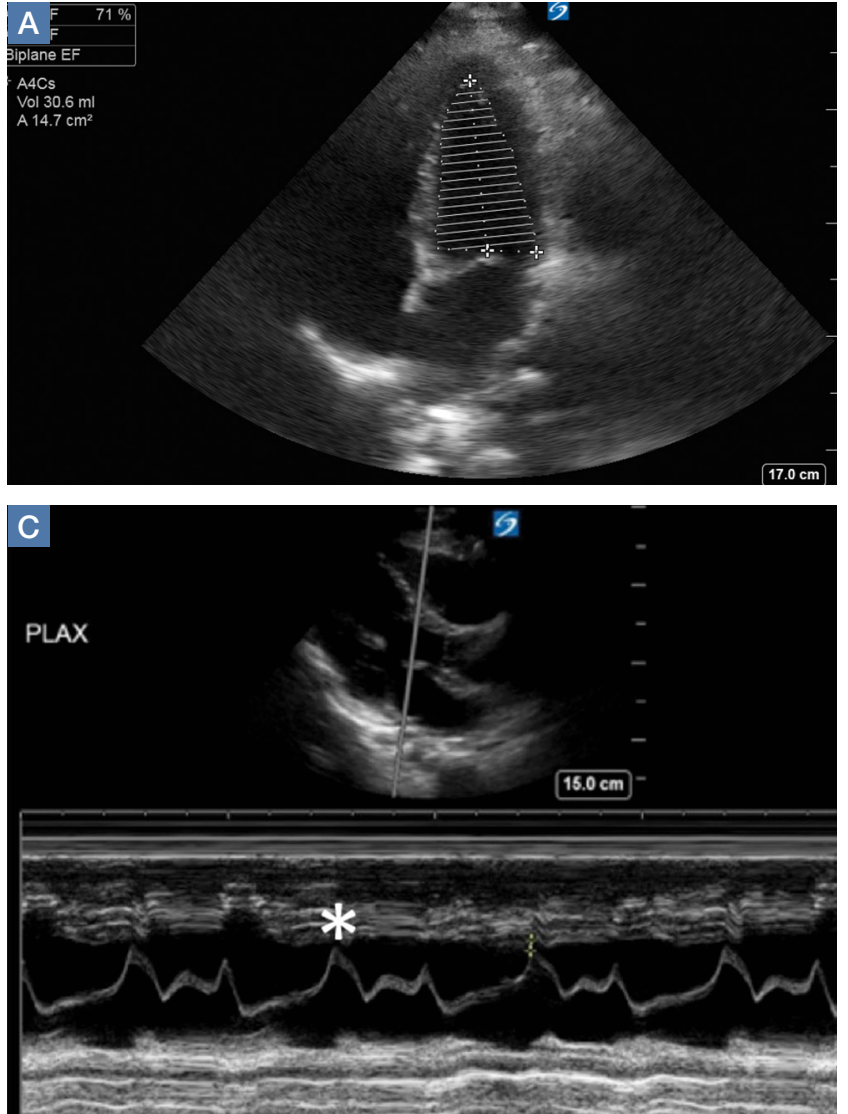

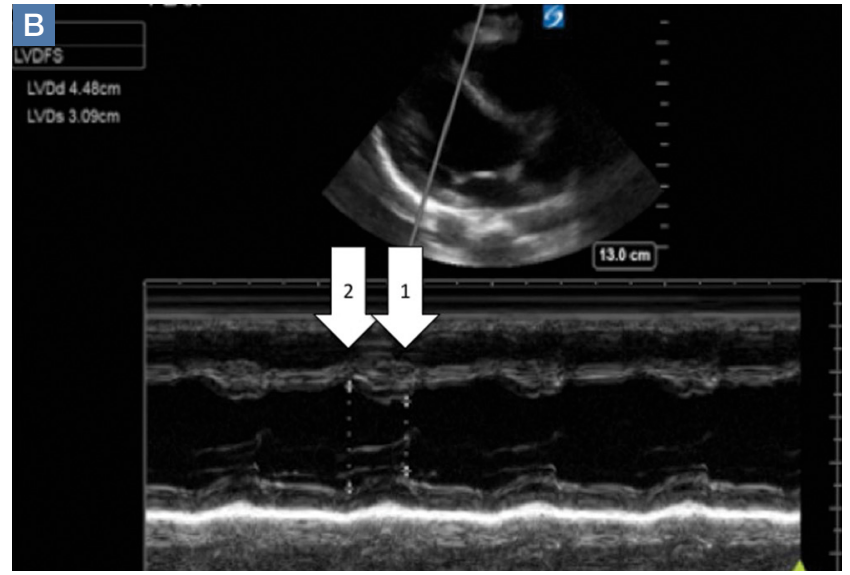

Figure 6. Echocardiographic images demonstrating (A) the Simpson's Rule to calculate ventricular volume by summing the volume of a series of discs filling the measured ventricular cavity on an apical four- (AP4) chamber view. After calculating the volume in both end-systole (ES) and end-diastole (ED), the cardiac package can determine the percent of change, providing an ejection fraction (EF). To account for threedimensional measurements of the septal-lateral walls as well as the anterior-inferior walls, this study needs to be performed in both AP4and apical two-chamber views with clear visualization of the endocardial borders for best accuracy. The EF is calculated by the following equation: (LV ED volume - LV ES volume)/LV ED volume x 100\%; (B) an example of a fractional shortening measurement in M-mode with the cursor perpendicular to left ventricular walls and measurements at ES (white arrow 1), and ED (white arrow 2); and (C) an example of E-point septal separation measurement with the M-mode cursor through the apical tip of the anterior leaflet (white asterisk) of the mitral valve in the parasternal long axis view. parasternal long axis (PLAX) view, the M-mode cursor is placed over the walls of the LV, just apical to the tips of the mitral valve (MV) leaflets (Figure 6b). Maximal (end-diastolic diameter [EDD]) and minimal (end-systolic diameter [ESD]) dimensions of the LV are measured and FS is calculated as (LVEDD - LVESD)/ LVEDD. A normal value is more than $25 \%$, and a rough estimate of EF is FS $\times 2 .{ }^{24} \mathrm{Limi}$ tations to this study include nonplacement of the M-mode cursor perpendicular to the LV walls, and inaccuracy in patients with regional wall abnormalities.

\section{E-Point Septal Separation}

Another way to assess EF with POCUS is through E-point septal separation (EPSS), which uses the movement of the MV during diastole to estimate the $\mathrm{EF}$ during systole. In the PLAX view, the M-mode cursor is placed over the apical tip of the anterior leaflet of the MV to visualize the movement of the leaflet in relation to the interventricular septum (Figure 6c). Two characteristic waves are created during each diastole-the larger first wave representing early filling (the E-wave) and the smaller second wave representing the atrial kick (the A-wave). The E-point is the tallest point of the E-wave, and the EPSS is measured as the distance in millimeters between the E-point and the interventricular septum. ${ }^{21}$

The opening of the anterior leaflet of the MV toward the interventricular septum in diastole requires a pressure difference between the left atrium (LA) and LV. In a patient with poor LV systolic function, the LV is still full at the end of systole, the pressure difference is not as great, and the mitral leaflets will not snap open vigorously. The EPSS should be at or less than $6 \mathrm{~mm}$ in patients with normal LV systolic function. An EPSS of 6 to $12 \mathrm{~mm}$ suggests moderately depressed LV systolic function, and over $12 \mathrm{~mm}$ signifies severely decreased LV systolic function. ${ }^{25}$ Limitations 

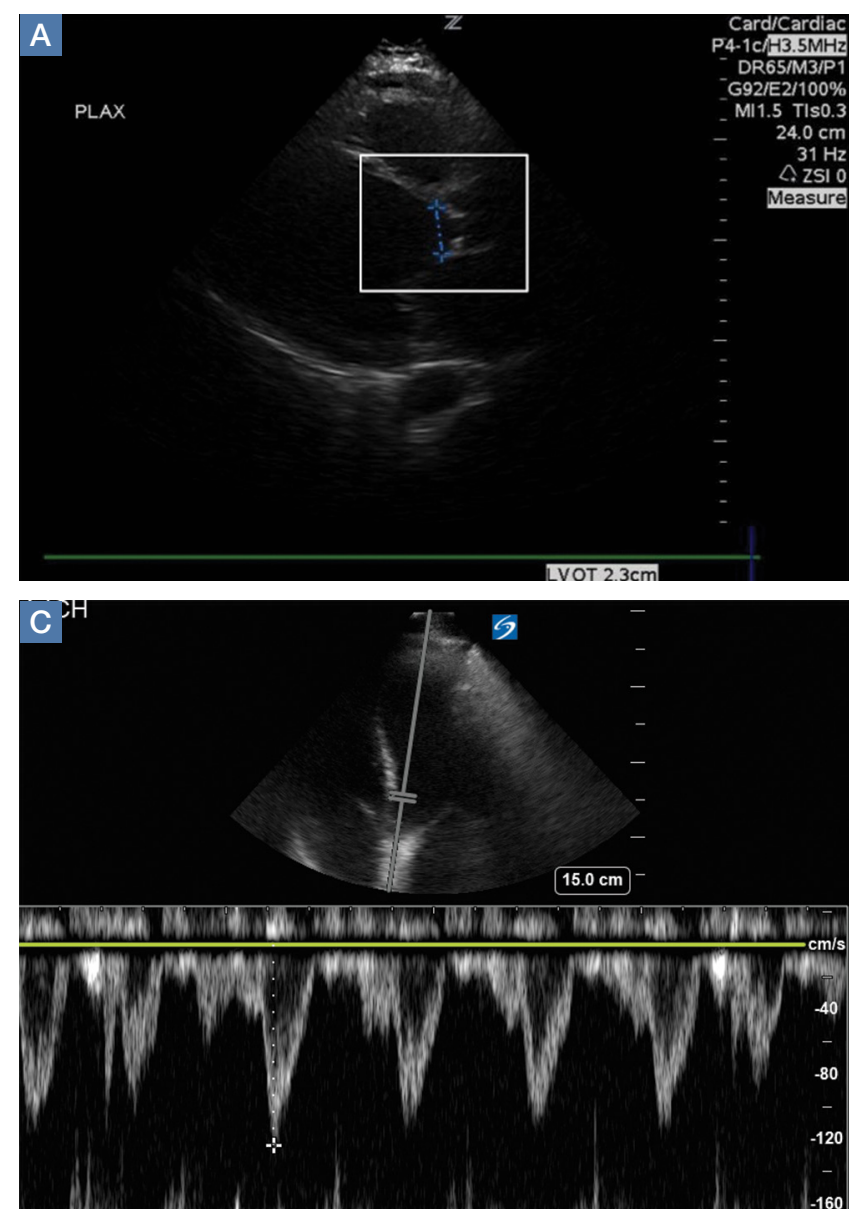

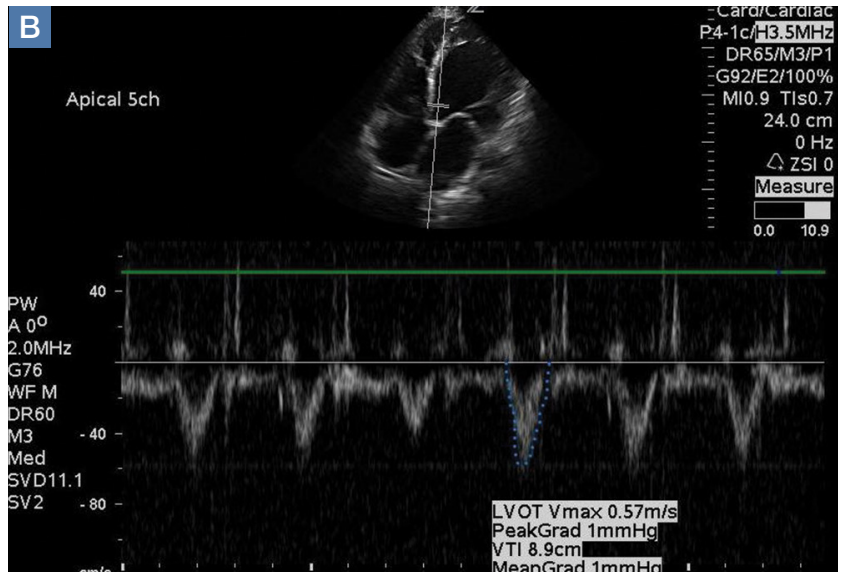

Figure 7. Transthoracic echocardiographic images demonstrating (A) the left ventricular outflow tract (LVOT) diameter (white box), obtained in midsystole in the parasternal long axis view where the right aortic valve cusp meets the interventricular septum to where the noncoronary aortic valve cusp meets the base of the anterior mitral valve leaflet in a line parallel to the aortic valve annulus; (B) LVOT velocity time integral (VTI), an estimation of the distance that a column of blood travels during one contraction, obtained using pulsed-wave Doppler interrogation of the LVOT in an apical five- (AP5) chamber view. (The angle of insonation must be less than $20^{\circ}$ to obtain reliable Doppler flow measurements. The resultant spectral Doppler signal is traced, and the area under the curve is calculated using the cardiac software to give the LVOT VTI. With the LVOT diameter and VTI, stroke volume [SV] can be calculated as follows: SV $=\pi[$ LVOT diameter/2] $2 \times$ [LVOT VTI]. Cardiac output is simply SV $x$ heart rate); and (C) the LVOT peak velocity variation, obtained in the AP5-chamber view using pulsedwave Doppler imaging. include inaccuracy in patients with valvular abnormalities, such as mitral stenosis or aortic regurgitation, severe LV or septal hypertrophy, regional wall abnormalities or severe LV dilation, limited data, and a wide margin of error when comparing to magnetic resonance imaging measurement of EF.

\section{Cardiac Output}

Cardiac output evaluation is another method to assess the hemodynamic status of the critically ill patient. The calculation requires three parameters: the $\mathrm{LV}$ outflow tract (LVOT) diameter, the LVOT VTI, and the patient's heart rate (HR) (Figures 7a7c) Limitations to this study are the assumption of symmetry of the LVOT, that a single diameter measurement will accurately estimate LVOT area, and that VTI measurements vary based on the angle of insonation. ${ }^{26}$

\section{Left Ventricular Diastolic Assessment}

In an aging population of patients who have longstanding, undiagnosed, or untreated hypertension, LV hypertrophy leads to impaired relaxation and diastolic filling, eventually causing elevated LA pressure and, in extreme cases, restrictive cardiomyopathy. It has been reported that approximately half of all symptomatic patients with heart failure have a preserved EF. ${ }^{27}$

Determination of LV pressures allows for the distinction between hydrostatic pulmonary edema and ARDS. Diagnosing elevated LA pressure is not inconsequential, as diastolic dysfunction in septic patients has been associated with increased mortality, likely due to increased pulmonary edema from fluid resuscitation. ${ }^{19}$ An invasive method of using a pulmonary artery catheter and measuring the pulmonary artery occlusion pressure to estimate the LA pres- 

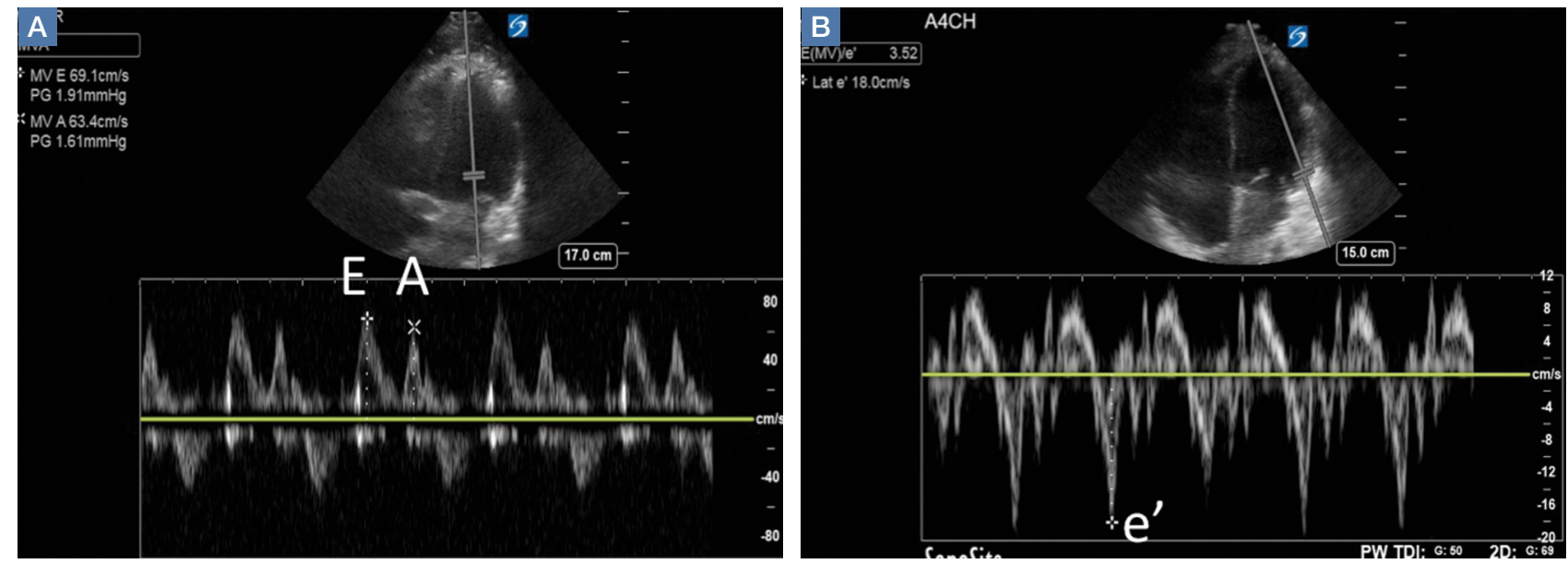

Figure 8. Echocardiographic images demonstrating (A) mitral valve (MV) inflow velocities (E- and A-waves), obtained in the apical four- (AP4) chamber view using pulsed-wave Doppler imaging with the interrogation gate just apical to tip of MV within the left ventricle; and (B) the early diastolic mitral annulus velocity (e') wave, obtained in the AP4-chamber view using tissue Doppler, which shows the speed of myocardial relaxation in diastole.

sure is the gold standard, but is no longer routinely performed.

Echocardiography is a noninvasive surrogate to estimating LA and LV filling pressures. Two different echocardiographic measurements can be used in conjunction to estimate LV filling pressures: MV inflow velocity and tissue Doppler imaging.

\section{Mitral Valve Inflow Velocity}

Assessment of the MV inflow is performed by placing the pulse-wave Doppler gate between the tips of the MV leaflets in the AP4 view. Early diastolic filling produces the Ewave, and LA contraction produces the late diastolic A-wave (Figure 8a). The interpretation of these waves can be categorized in four patterns: (1) normal; (2) abnormal relaxation; (3) pseudonormalization; and (4) restrictive. The mitral inflow pattern for normal and pseudonormalization are very similar, and other techniques are used to differentiate them, such as the E-wave/A-wave (E/A) ratio, deceleration time, or alternatively, using either tissue Doppler imaging or pulmonary vein Doppler analysis.

\section{Tissue Doppler Imaging}

Tissue Doppler imaging enables the clinician to measure myocardial velocities such as the speed of relaxation to evaluate if $\mathrm{LV}$ relaxation is due to a drop in $\mathrm{LV}$ pressure below LA pressure after systole, pulling the MV open; or if increased LA pressure is required to push open the MV and fill the LV.

For this study, the tissue Doppler sampling gate is placed at the septal or lateral annulus of the MV in the AP4 view to visualize early diastolic mitral annulus velocity (e') (Figure 8b). The E/e' ratio can be helpful for estimating LV filling pressures. An $\mathrm{E} / \mathrm{e}$ ' of less than 8 is associated with normal LV filling pressure whereas an E/e' $>15$ is associated with an elevated LV filling pressure. ${ }^{28,29}$ When the $\mathrm{E} / \mathrm{e}$ ' is 8 to 10 , other indices such as the E/A ratio and deceleration time, as well as the clinical picture, can provide insight into the presence of hemodynamically significant diastolic dysfunction.

Learning and applying the assessment of diastolic parameters can be challenging; however, these parameters can be used to help predict LV filling pressures in patients with findings of pulmonary edema on chest radiograph. Limitations of these techniques are inter-rater variability, as well as the ability of the operator to acquire the required AP4 view. In addition, these techniques are unreliable in patients with irregular cardiac rhythms, severe mitral disease, and in hypertrophic cardiomyopathy.

\section{Right Ventricular Assessment}

The right ventricle (RV) is a small, thinwalled ventricle with only two layers of muscle, as opposed to the three layers of the 

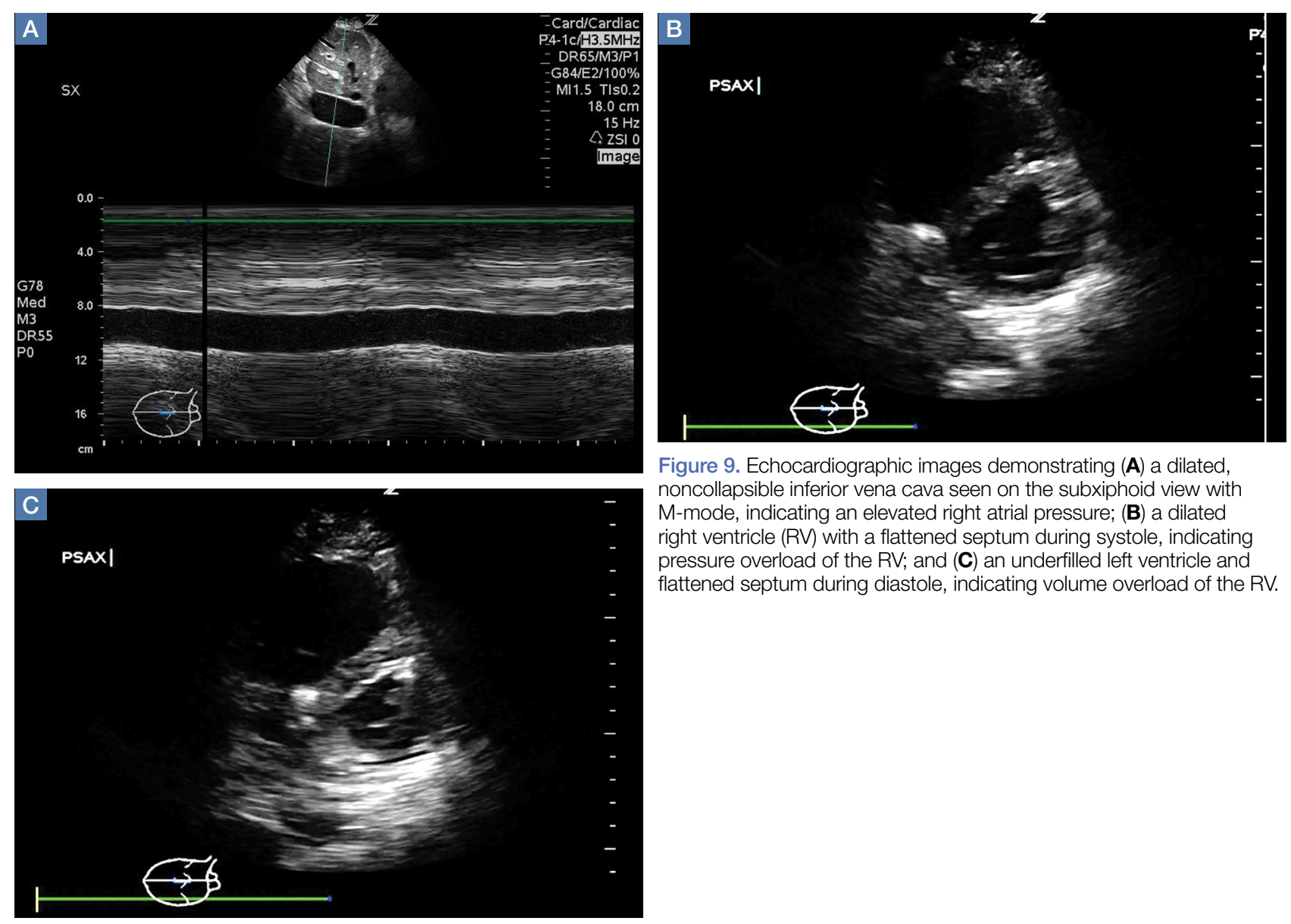

Figure 9. Echocardiographic images demonstrating $(\mathbf{A})$ a dilated noncollapsible inferior vena cava seen on the subxiphoid view with M-mode, indicating an elevated right atrial pressure; (B) a dilated right ventricle (RV) with a flattened septum during systole, indicating pressure overload of the RV; and (C) an underfilled left ventricle and flattened septum during diastole, indicating volume overload of the RV.

$\mathrm{LV}$. In contrast to the rocking motion of $\mathrm{LV}$ contraction, the orientation of the two muscle layers of the RV permits mostly longitudinal contraction. The circumferential muscle fibers are shared at the base and apex with the LV, which can provide some of the contractile strength of the RV. ${ }^{30}$ Because of this orientation, RV strain, which can manifest as decreased longitudinal contraction, speed of contraction, septal movement, and tethering abnormalities through ventricular interdependence, can be measured easily using bedside echocardiography.

In healthy individuals, the RV is a lowpressure chamber that acts as a conduit for propelling venous return into the pulmonary circulation without much effect on systemic hemodynamics. However, in critical illness, RV abnormalities can have profound effects on hemodynamics, and the efforts typically used to improve LV performance will worsen a failing RV.
While RV dysfunction is most commonly due to chronic LV disease, acute RV dysfunction is commonly encountered in critical illness, ${ }^{31}$ including many septic patients with ARDS, ${ }^{32,33} \mathrm{PE}$, or decompensated chronic pulmonary hypertension. ${ }^{34}$ The examinations that follow, allow the EP to assess for the presence of RV dysfunction and to guide resuscitation appropriately to avoid the untoward hemodynamic effects of conventional resuscitation strategies in these patients.

When evaluating the RV, the clinician must determine (1) if the patient's RV strain is due to pressure or volume overload; and (2) if the patient's RV is responsive or nonresponsive to a preload challenge, prompting an alteration in the resuscitation plan in nonresponsive cases.

\section{Right Ventricular Pressure/Nolume Overload} While inferior vena cava (IVC) ultrasound has been shown to be a pre-heart/lung as- 
sessment of cardiopulmonary interactions that predicts volume responsiveness, the IVC is also a good predictor of right atrial (RA) pressure. ${ }^{35}$ If the IVC is dilated and lacks respiratory variation, the patient likely has an elevated RA pressure, which is most likely transmitted from an elevated RV pressure (Figure 9a). However, compliance of the RA, RA pressure and, by extension, IVC prediction of that RA pressure, may underestimate the degree of RV pressure or afterload.

In the presence of pressure overload of the RV, septal motion will be toward the $\mathrm{LV}$ and flatten during systole (Figure $\mathbf{9 b}$ ). Despite movement of the septum toward the LV on systole, the LV is still able to fill in diastole and maintain an adequate cardiac output (often with concomitant tachycardia). When the RV is volume-overloaded, the septum flattens on diastole, which has a more deleterious effect on cardiac output (Figure 9c). Due to pericardial restraint on the free wall of the LV, the LV is unable to fill during diastole and thus cardiac output drops. ${ }^{30,36}$ The well-known "D-sign" occurs when the RV is both pressure- and volume-overloaded, which often occurs when a hypotensive patient with a pressure-overloaded RV receives a bolus of fluid. McConnell's sign occurs when the pressure and volume-overloaded RV has apical "blinking" caused by tethering of the shared muscle fibers with the $\mathrm{LV}^{37}$

\section{Right Ventricular Strain and Contractile Reserve}

The longitudinal contraction of the RV can be easily measured on bedside ultrasound. In the apical view, M-mode imaging through the lateral annulus of the tricuspid valve will provide a measurement of the systolic movement of the RV. Increased strain on the RV will lead to decreased tricuspid annular plane systolic excursion (Figure 10a). ${ }^{38}$

From the same apical view, tissue Doppler at the lateral tricuspid annulus will give a tricuspid annular peak velocity, a measure of the isovolumetric contraction velocity. This measurement will provide a measure of the contractile reserve of the RV (Figure 10b). A measure of less than 10 $\mathrm{cm} / \mathrm{sec}$ indicates that further volume and inotropic challenges to the RV will not be effective, and the focus should be to decrease RV afterload with pulmonary vasodilators. $^{34,39,40}$

\section{Fluid Resuscitation Assessment}

Restoring circulating volume to increase cardiac output and improve oxygen delivery is the primary objective when managing patients in shock. Patient outcomes improve dramatically with early aggressive fluid resuscitation. ${ }^{41-44}$ However, many critically ill patients do not respond to fluid resuscitation, which is generally defined as the rise of cardiac output of more than $15 \%$ in response to volume expansion. Not all patients found to be fluid responsive will require volume expansion. ${ }^{45,46}$

Excessive fluid resuscitation has been shown to increase intensive care unit length of stay, morbidity, and mortality. ${ }^{47,48}$ Further, pathophysiological processes such as RV dysfunction and severe diastolic dysfunction can significantly alter the hemodynamic profile such that fluid management can be quite challenging in critically ill patients.

Distinguishing responders from nonresponders prior to fluid administration is the goal of early resuscitation. Unfortunately, this distinction cannot be made based on the patient's vital signs or the physical examination. ${ }^{49}$ Static filling pressures and volumetric measures are unreliable markers of fluid responsiveness. ${ }^{50,51}$ The practice of administering a fluid challenge and observing the clinical effect on cardiac output is undesirable because it requires, by definition, on administering fluids, which ultimately may be harmful to the patient.

Dynamic measures of fluid responsiveness that reliably predict cardiac response to a preload challenge are proven to be of 

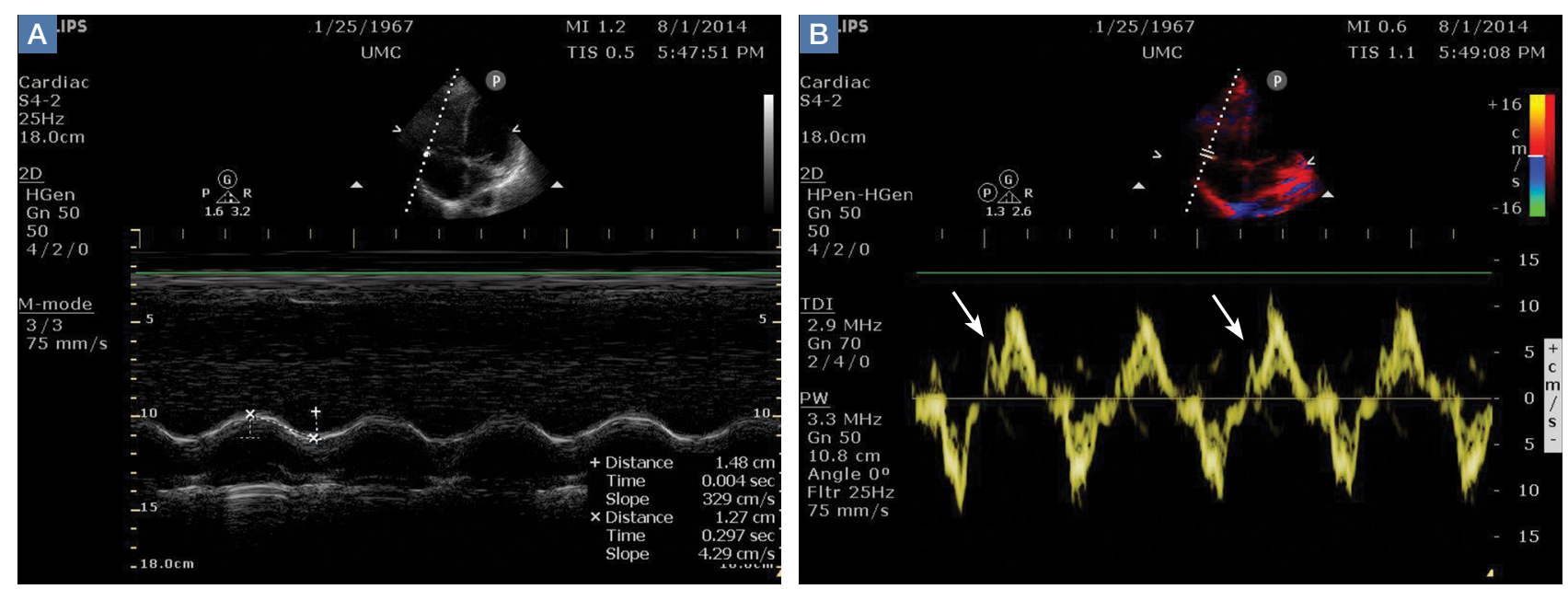

Figure 10. Echocardiographic images demonstrating (A) the tricuspid annular plane systolic excursion (TAPSE), which measures the longitudinal contraction of the right ventricle (RV) an assessment of the degree of strain on the RV (a TAPSE $<16 \mathrm{~mm}$ indicates strain on the RV); (B) the isovolumetric contraction velocity (white arrows) using tissue Doppler at the same point of the lateral tricuspid annulus, measuring the speed of $\mathrm{RV}$ contraction prior to the opening of the pulmonic valve- a measure of the contractile reserve of the RV to respond to increased preload or inotropic medications (a contraction velocity $<10 \mathrm{~cm} / \mathrm{sec}$ indicates poor contractile reserve and that further fluid resuscitation is likely to result in further RV failure).

greater utility. ${ }^{52,53}$ These assessments determine volume responsiveness by evaluating the change in LV output with intrathoracic pressure changes due to the respiratory cycle, (ie, cardiopulmonary interaction). Ultrasound studies to assess cardiopulmonary interactions include IVC variability, arterial flow variability, brachial artery peak velocity variability, and common carotid artery (CCA) flow. In addition to echocardiography, lung ultrasound may be used to determine the endpoint of fluid resuscitation by monitoring for the appearance of extravascular lung water.

\section{Inferior Vena Cava Variability}

The IVC is a large extrathoracic vein which is easily insonated and accessible, even to a clinician with basic bedside ultrasound competency. Static IVC measures, such as diameter alone, correlate with central venous pressure but do not predict fluid responsiveness. ${ }^{54-56}$ Dynamic IVC evaluation provides an upstream assessment of cardiopulmonary interactions.

The IVC can be seen in several planes, but is most commonly evaluated in the subxiphoid long axis view. The diameter is best measured between the entry of the hepatic and renal veins (Figure 11). ${ }^{57}$ It is important to be aware of the potential for both vertical and horizontal translation of the IVC during the respiratory cycle. ${ }^{58}$

In the spontaneously breathing patient, the IVC collapses with inspiration as the RA pressure falls below atmospheric pressure, collapsing the intrathoracic veins for a short period until the intravascular pressure at the entry to the thorax exceeds atmospheric pressure, causing a bolus of venous return to the right heart. The overall effect is an increase in venous return ${ }^{59}$ Conversely, in the mechanically ventilated patient, the IVC will distend with insufflation as increased intrathoracic pressure results in increased RV afterload and a transient increase in pulmonary artery pressure with an overall net decrease in venous return..$^{60}$

This IVC variability, termed the caval index, quantifies the degree of change in size of the IVC between end-inspiration and end-expiration. An M-mode imaging evaluation of the IVC allows for measurement of the maximal and minimal diameters for this calculation (Figure 11). Passively mechanically ventilated patients, with tidal volumes (TV) of 8 to $10 \mathrm{cc} / \mathrm{kg}$ in sinus rhythm, are predictably volumeresponsive when the IVC distends by $12 \%$ to $18 \% .^{54,61,62}$ However, there is considerable debate as to whether evaluating 


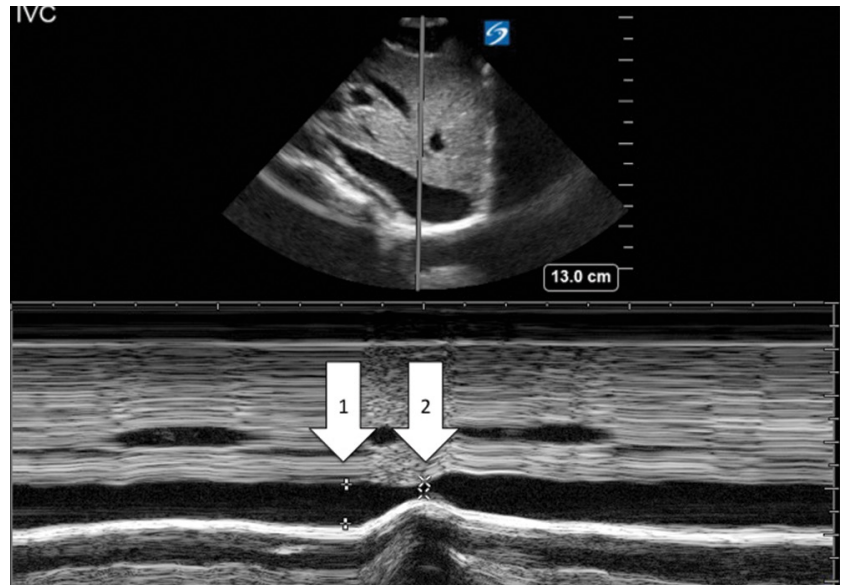

Figure 11. Echocardiographic image demonstrating a change in diameter of the inferior vena cava (IVC) during inspiration or sniffing in a spontaneously breathing patient. Arrow 1 represents the maximum diameter, and Arrow 2, the minimum diameter. (The maximum diameter-minimum diameter)/maximum diameter = percent of change, also known as the caval index, a rough approximation of right atrial pressures. the degree of IVC collapse is of value in spontaneously breathing patients. ${ }^{63}$ Cardiopulmonary interactions that drive IVC variability are affected by variable TV, intrathoracic pressure changes, etc. Nonetheless, two studies have shown that IVC collapse reliably predicts fluid responsiveness in spontaneously breathing patients. ${ }^{64,65}$

\section{Stroke Volume/Arterial Flow Variability}

Intrathoracic pressure changes induce dynamic changes in venous return that ultimately result in alterations in LV stroke volume (LVSV) when the blood volume traverses pulmonary circulation. ${ }^{66}$ This variability in LVSV is the basis for all dynamic assessments of cardiopulmonary interactions, whether by arterial pressure waveform analysis or echocardiographic assessment of arterial flow.

The LVSV variability reliably predicts fluid responsiveness and may be assessed by esophageal Doppler echocardiography of the ascending aorta. ${ }^{67,68}$ Transesophageal echocardiography has also been used to assess SV variability at the LVOT. ${ }^{69}$ Both of these measures require equipment and skill that may not be available in every clinical setting. Fortunately, LVOT SV is easily obtained through transthoracic echocardiography (TTE) (Figures 7a and 7b) using LVOT Doppler velocities as a surrogate for SV variations. A small study of TTE in mechanically ventilated children found that aortic flow variability predicted fluid responsiveness. ${ }^{70}$ Therefore, transthoracic echocardiography provides a well-established alternative to thermodilution in determining cardiac output. Multiplication of the HR by an estimate of the column of blood flowing through the LVOT with each systolic contraction gives the cardiac output. ${ }^{71}$

Using TTE measurement of SV and cardiac output, the clinician can assess the effect of small fluid challenges on cardiac output. ${ }^{72}$ Cardiac output can be augmented with the passive leg raise (PLR), which is an entirely reversible preload challenge maneuver thought to increase preload by 300 to $500 \mathrm{~mL}$. To assess volume responsiveness using this technique, LVOT cardiac output must first be determined. With the transducer in place, the patient's legs are lifted to a $45^{\circ}$ angle. After a minute of equilibration, the LVOT VTI is repeated and cardiac output recalculated. An increase in VTI of more than $12.5 \%$ predicts an increase in cardiac output with volume expansion. ${ }^{73,74}$ This procedure requires proficiency with pulsed-wave Doppler and the ability to obtain the apical fivechamber view while a patient's legs are being manipulated. In addition, the angle of insonation and location of measurement of LVOT and VTI must not vary for this measure to be valid.

Alternatively, respiratory variation in LVOT peak velocities has been shown to reliably predict volume responsiveness when variability is more than $12 \%$ (Figure 7c) ${ }^{69}$ This measurement is easier to obtain in that it does not require multiple views or complex calculations, and can be easily augmented with a passive leg raise maneuver.

\section{Brachial Artery Peak Velocity Variation}

In the search for easily accessible alternatives to cardiac and aortic flow, brachial ar- 
tery peak velocity variation (BAPVV) was found to be useful for predicting volume responsiveness. ${ }^{75}$ To perform this study, the brachial artery is imaged in the long axis view using a linear transducer. Doppler gating should be adjusted to ensure an angle of less than $60^{\circ}$. The patient's BAPVV is calculated as the difference between maximum and minimum peak velocity divided by the mean peak velocity. A variability in peak velocity of more than $10 \%$ predicts volume responsiveness. ${ }^{75}$

\section{Common Carotid Artery Flow}

Similarly, CCA flow has attracted attention as a potential surrogate to assess SV response to preload challenge. ${ }^{76,77}$ The CCA is large, easily accessible and does not require specialized training to assess (Figure 12). ${ }^{78}$ One study found patients to be fluid responsive with a $94 \%$ specificity and an $86 \%$ sensitivity if they had a $20 \%$ increase in carotid flow after PLR. ${ }^{79}$

Even though cardiopulmonary interaction assessment has excellent performance for predicting volume responsiveness, limitations do exist. For example, cardiopulmonary interactions may be exaggerated or diminished-thus decreasing the reliability of this assessment-in patients on mechanical ventilation who have spontaneous breathing, high positive end-expiratory pressures or a high minute ventilation, low TV, dysrhythmias, external compression of extra- or intrathoracic vessels (eg, intra-abdominal hypertension, pericardial tamponade, COPD/asthma exacerbations); and in patients who have decreased arterial elastance, or high RV afterload causing $\mathrm{RV}$ dysfunction or failure.

\section{Conclusion}

The advanced ultrasound techniques described in this review provide several useful tools to rapidly evaluate and manage cardiopulmonary interactions and assess the hemodynamic profile of critically ill patients. With these bedside techniques added to basic POCUS examinations, a

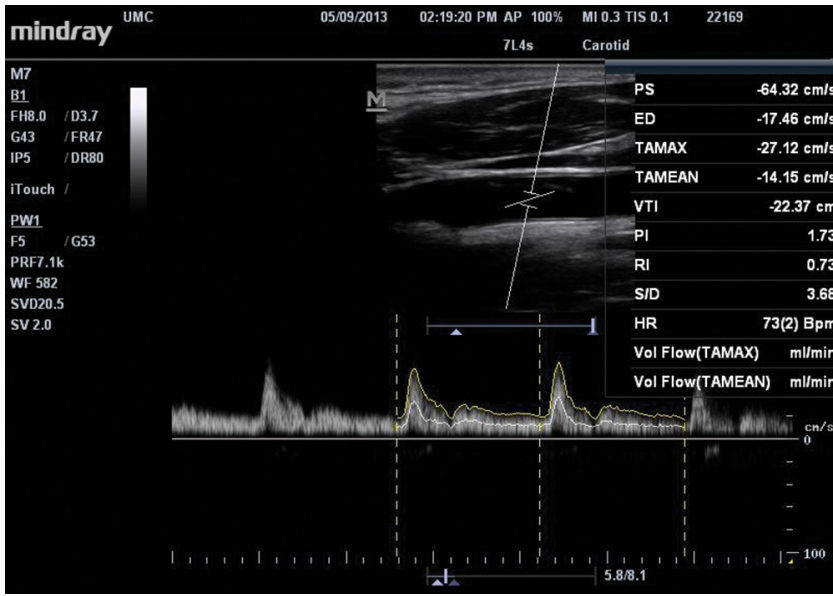

Figure 12. Echocardiographic images demonstrating carotid velocities, which are measured by first obtaining the diameter of the vessel in short axis during systole within $0.5 \mathrm{~cm}$ of the bulb. The common carotid artery (CCA) velocity time integral (VTI) is measured at the same level, in long axis, with gating in the middle of the artery and an angle of insonation of $45^{\circ}-60^{\circ}$; CCA flow is calculated as (CCA diameter) $)^{2} /(4$ $x \mathrm{VTI} \times$ heart rate).

new era in noninvasive critical care management is now available.

As we enter the days of precision medicine, these examinations will enable EPs to optimize the care of this high-risk patient population. Moreover, future research by the emergency ultrasound and critical care communities on morbidity and mortality associated with resuscitation strategies in the ED will undoubtedly incorporate cardiopulmonary and hemodynamic ultrasound.

\section{References}

1. Kanji HD, McCallum J, Sirounis D, MacRedmond R, Moss R, Boyd JH. Limited echocardiography-guided therapy in subacute shock is associated with change in management and improved outcomes. J Crit Care. 2014;29(5):700-705. doi:10.1016/j.jcrc.2014.04.008.

2. Raja AS, Jacobus CH. How accurate is ultrasonography for excluding pneumothorax? Ann Emerg Med. 2013;61(2):207-208. doi:10.1016/j.annemergmed.2012.07.005.

3. Alrajhi K, Woo MY, Vaillancourt C. Test characteristics of ultrasonography for the detection of pneumothorax: a systematic review and analysis. Chest. 2012;141(3):703-708. doi:10.1378/chest.11-0131.

4. Blaivas M, Lyon M, Duggal S. A prospective comparison of supine chest radiography and bedside ultrasound for the diagnosis of traumatic pneumothorax. Acad Emerg Med. 2005;12(9):844-849. doi:10.1197/j. aem.2005.05.005.

5. Zanobetti M, Poggioni C, Pini R. Can chest ultrasonography replace standard chest radiography for evaluation of acute dyspnea in the ED? Chest. 2011;139(5):1140-1147.

6. Lichtenstein D, Goldstein I, Mourgeon E, Cluzel P, Grenier P, Rouby JJ. Comparative diagnostic performances of auscultation, chest radiography, and lung ultrasonography in acute respiratory distress syndrome. Anesthesiology. 2004;100(1):9-15. 
7. Xirouchaki N, Magkanas E, Vaporidi K, et al. Lung ultrasound in critically ill patients: comparison with bedside chest radiography. Intensive Care Med. 2011;37(9):1488-1493. doi:10.1007/s00134-0112317-y.

8. Lichtenstein DA. Lung ultrasound in the critically ill. Ann Intensive Care. 2014;4(1):1.

9. Lichtenstein DA, Mezière G, Lascols N, et al. Ultrasound diagnosis of occult pneumothorax. Crit Care Med. 2005;33(6):1231-1238.

10. Slater A, Goodwin M, Anderson KE, Gleeson FV. COPD can mimic the appearance of pneumothorax on thoracic ultrasound. Chest. 2006;129(3):545-550. doi:10.1378/chest.129.3.545.

11. Lichtenstein DA, Lascols N, Prin S, Mezière G. The "lung pulse": an early ultrasound sign of complete atelectasis. [published online ahead of print October 14, 2003]. Intensive Care Med. 2003;29(12):21872192. doi:10.1007/s00134-003-1930-9.

12. Lichtenstein D. Fluid administration limited by lung sonography: the place of lung ultrasound in assessment of acute circulatory failure (the FALLSprotocol). Expert Rev Respir Med. 2012;6(2):155-162. doi:10.1586/ers.12.13.

13. Lichtenstein D, Mezière G. A lung ultrasound sign allowing bedside distinction between pulmonary edema and COPD: the comet-tail artifact. Intensive Care Med. 1998;24(12):1331-1334.

14. Dickman E, Terentiev V, Likourezos A, Derman A Haines L. Extension of the thoracic spine sign: a new sonographic marker of pleural effusion. [published online ahead of print August 12, 2015]. J Ultrasound Med. 2015;34(9):1555-1561. doi:10.7863/ ultra.15.14.06013.

15. Noble VE, Murray AF, Capp R, Sylvia-Reardon MH, Steele DJ, Liteplo A. Ultrasound assessment for extravascular lung water in patients undergoing hemodialysis. Time course for resolution. [published online ahead of print February 2, 2009]. Chest. 2009;135(6):1433-1439. doi:10.1378/chest.08-1811.

16. Lichtenstein D. Lung and Interstitial Syndrome. In: Lichtenstein D, ed. Whole Body Ultrasonography in the Critically IIl. New York, NY: Springer; 2010: 151-157.

17. Lichtenstein DA, Mezière GA, Lagoueyte JF, Biderman P, Goldstein I, Gepner A. A-lines and B-lines: lung ultrasound as a bedside tool for predicting pulmonary artery occlusion pressure in the critically ill. Chest. 2009;136(4):1014-1020. doi:10.1378/ chest.09-0001.

18. Romero-Bermejo FJ, Ruiz-Bailen M, Gil-Cebrian J, Huertos-Ranchal MJ. Sepsis-induced cardiomyopathy. Curr Cardiol Rev. 2011;7(3):163-183

19. Sanfilippo F, Corredor C, Fletcher N, et al. Diastolic dysfunction and mortality in septic patients: a systematic review and meta-analysis. [published online ahead of print March 24, 2015]. Intensive Care Med. 2015;41(6):1004-1013. doi:10.1007/s00134-0153748-7.

20. Randazzo MR, Snoey ER, Levitt MA, Binder K. Accuracy of emergency physician assessment of left ventricular ejection fraction and central venous pressure using echocardiography. Acad Emerg Med. 2003;10(9):973-977.

21. Reardon R. Cardiac. In: Ma O, Mateer J, eds. Emergency Ultrasound. 2nd ed. New York, NY: McGraw Hill Companies, Inc; 2008:114-115.

22. Martindale JL, Wakai A, Collins SP, et al. Diagnosing acute heart failure in the emergency department: a systematic review and meta-analysis. [published online ahead of print February 13, 2016]. Acad Emerg Med. 2016;23(3):223-242 doi:10.1111/acem.12878.

23. Cerqueira MD, Weissman NJ, Dilsizian V, et al;
American Heart Association Writing Group on Myocardial Segmentation and Registration for Cardiac Imaging. Standardized myocardial segmentation and nomenclature for tomographic imaging of the heart. A statement for healthcare professionals from the Cardiac Imaging Committee of the Council on Clinical Cardiology of the American Heart Association. Circulation. 2002;105(4):539-542.

24. Lang RM, Bierig M, Devereux RB, et al. Recommendations for chamber quantification. [published online ahead of print February 2, 2006]. Eur J Echocardiogr. 2006;7(2):79-108. doi:10.1016/j. euje.2005.12.014.

25. Secko MA, Lazar JM, Salciccioli LA, Stone MB. Can junior emergency physicians use E-point septal separation to accurately estimate left ventricular function in acutely dyspneic patients? [published online ahead of print November 1, 2011]. Acad Emerg Med. 2011;18(11):1223-1226. doi:10.1111/j.15532712.2011.01196.x.

26. Dinh VA, Ko HS, Rao R, et al. Measuring cardiac index with a focused cardiac ultrasound examination in the ED. [published online ahead of print July 12, 2012]. Am J Emerg Med. 2012;30(9):1845-1851. doi:10.1016/j.ajem.2012.03.025.

27. Owan TE, Hodge DO, Herges RM, Jacobsen SJ, Roger VL, Redfield MM. Trends in prevalence and outcome of heart failure with preserved ejection fraction. $N$ Engl J Med. 2006;355(3):251-259. doi:10.1056/NEJMoa052256.

28. Nagueh SF, Appleton CP, Gillebert TC, et al. Recommendations for the evaluation of left ventricular diastolic function by echocardiography. J Am Soc Echocardiogr. 2009;22(2):107-133. doi:10.1016/j. echo.2008.11.023.

29. Ommen SR, Nishimura RA. A clinical approach to the assessment of left ventricular diastolic function by Doppler echocardiography: update 2003. Heart. 2003;89 Suppl 3:iii18-23.

30. Haddad F, Hunt SA, Rosenthal DN, Murphy DJ. Right ventricular function in cardiovascular disease, part I: anatomy, physiology, aging, and functional assessment of the right ventricle. Circulation. 2008;117(11):1436-1448. doi:10.1161/CIRCULATIONAHA.107.653576.

31. Zochios V, Jones N. Acute right heart syndrome in the critically ill patient. Heart Lung Vessel. 2014;6(3):157-170.

32. Mekontso Dessap A, Boissier F, Charron C, et al. Acute cor pulmonale during protective ventilation for acute respiratory distress syndrome: prevalence, predictors, and clinical impact. [published online ahead of print December 9, 2015]. Intensive Care Med. 2016;42(5):862-870. doi:10.1007/s00134-0154141-2.

33. Jardin F, Gueret P, Dubourg O, Farcot JC, Margairaz A, Bourdarias JP. Two-dimensional echocardiographic evaluation of right ventricular size and contractility in acute respiratory failure. Crit Care Med. 1985;13(11):952-956.

34. Dalabih M, Rischard F, Mosier JM. What's new: the management of acute right ventricular decompensation of chronic pulmonary hypertension. [published online ahead of print September 3, 2014]. Intensive Care Med. 2014;40(12):1930-1933. doi:10.1007/ s00134-014-3459-5.

35. Brennan JM, Blair JE, Goonewardena S, et al. Reappraisal of the use of inferior vena cava for estimating right atrial pressure. J Am Soc Echocardiogr. 2007;20(7):857-861. doi:10.1016/j.echo.2007.01.005.

36. Haddad F, Doyle R, Murphy DJ, Hunt SA. Right ventricular function in cardiovascular disease, part II: pathophysiology, clinical importance, and 
management of right ventricular failure. Circulation. 2008;117(13):1717-1731. doi:10.1161/CIRCULATIONAHA.107.653584.

37. McConnell MV, Solomon SD, Rayan ME, Come PC, Goldhaber SZ, Lee RT. Regional right ventricular dysfunction detected by echocardiography in acute pulmonary embolism. Am J Cardiol. 1996;78(4): 469-473.

38. Gajanana D, Seetha Rammohan H, Alli O, et al. Tricuspid annular plane systolic excursion and its association with mortality in critically ill patients. [published online ahead of print March 1, 2015]. Echocardiography. 2015;32(8):1222-1227. doi:10.1111/echo.12926.

39. Rudski LG, Lai WW, Afilalo J, et al. Guidelines for the echocardiographic assessment of the right heart in adults: a report from the American Society of Echocardiography endorsed by the European Association of Echocardiography, a registered branch of the European Society of Cardiology, and the Canadian Society of Echocardiography. J Am SoC Echocardiogr. 2010;23(7):685-713; quiz 786-788. doi:10.1016/j.echo.2010.05.010.

40. Vogel M, Schmidt MR, Kristiansen SB, et al. Validation of myocardial acceleration during isovolumic contraction as a novel noninvasive index of right ventricular contractility: comparison with ventricular pressure-volume relations in an animal model. Circulation. 2002;105(14):1693-1699.

41. Rivers E, Nguyen B, Havstad S, et al. Early goaldirected therapy in the treatment of severe sepsis and septic shock. N Engl J Med. 2001;345(19):13681377. doi:10.1056/NEJMoa010307.

42. Peake SL, Delaney A, Bailey M, et al; ARISE Investigators, ANZICS Clinical Trials Group. Goal-directed resuscitation for patients with early septic shock. [published online ahead of print October 1, 2014]. N Engl J Med. 2014;371(16):1496-1506. doi:10.1056/ NEJMoa1404380.

43. Yealy DM, Kellum JA, Huang DT, et al; ProCESS Investigators. A randomized trial of protocolbased care for early septic shock. [published online ahead of print March 18, 2014]. N Engl J Med. 2014;370(18):1683-1693. doi:10.1056/NEJMoa1401602.

44. Mouncey PR, Osborn TM, Power GS, et al. Trial of early, goal-directed resuscitation for septic shock. [published online ahead of print March 17, 2015] N Engl J Med. 2015;372(14):1301-1311. doi:10.1056/ NEJMoa1500896.

45. Marik PE, Lemson J. Fluid responsiveness: an evolution of our understanding. [published online ahead of print February 16, 2014]. Br J Anaesth. 2014;112(4):617-620. doi:10.1093/bja/aet590.

46. Marik PE. Fluid Responsiveness and the Six Guiding Principles of Fluid Resuscitation. Crit Care Med. 2016;44(10):1920-1922. doi:10.1097/ CCM.0000000000001483.

47. Boyd JH, Forbes J, Nakada TA, Walley KR, Russell JA. Fluid resuscitation in septic shock: a positive fluid balance and elevated central venous pressure are associated with increased mortality. Crit Care Med. 2011;39(2):259-265. doi:10.1097/ CCM.0b013e3181feeb15.

48. Wiedemann HP, Wheeler AP, Bernard GR, et al; National Heart, Lung, and Blood Institute Acute Respiratory Distress Syndrome (ARDS) Clinical Trials Network. Comparison of two fluid-management strategies in acute lung injury. [published online ahead of print May 21, 2006]. $N$ Engl J Med. 2006;354(24):2564-2575. doi:10.1056/NEJMoa062200.

49. McGee S, Abernethy WB 3rd, Simel DL. The rational clinical examination. Is this patient hypovolemic? JAMA. 1999;281(11):1022-1029.

50. Marik PE, Cavallazzi R. Does the central venous pressure predict fluid responsiveness? An updated meta-analysis and a plea for some common sense. Crit Care Med. 2013;41(7):1774-1781. doi:10.1097/ CCM.0b013e31828a25fd.

51. Osman D, Ridel C, Ray P, et al. Cardiac filling pressures are not appropriate to predict hemodynamic response to volume challenge. Crit Care Med. 2007;35(1):64-68. doi:10.1097/01 CCM.0000249851.94101.4F.

52. Marik PE, Cavallazzi R, Vasu T, Hirani A. Dynamic changes in arterial waveform derived variables and fluid responsiveness in mechanically ventilated patients: a systematic review of the literature. Crit Care Med. 2009;37(9):2642-2647. doi:10.1097/ CCM.0b013e3181a590da.

53. Michard F, Teboul JL. Predicting fluid responsiveness in ICU patients: a critical analysis of the evidence. Chest. 2002;121(6):2000-2008.

54. Feissel M, Michard F, Faller JP, Teboul JL. The respiratory variation in inferior vena cava diameter as a guide to fluid therapy. [published online ahead of print March 25, 2004]. Intensive Care Med. 2004;30(9):1834-1837. doi:10.1007/s00134-0042233-5.

55. Marik PE, Baram M, Vahid B. Does central venous pressure predict fluid responsiveness? A systematic review of the literature and the tale of seven mares. Chest. 2008;134(1):172-178. doi:10.1378/ chest.07-2331.

56. Nagdev AD, Merchant RC, Tirado-Gonzalez A, Sisson CA, Murphy MC. Emergency department bedside ultrasonographic measurement of the caval index for noninvasive determination of low central venous pressure. [published online ahead of print June 25, 2009]. Ann Emerg Med. 2010;55(3):290-295. doi:10.1016/j.annemergmed.2009.04.021.

57. Wallace DJ, Allison M, Stone MB. Inferior vena cava percentage collapse during respiration is affected by the sampling location: an ultrasound study in healthy volunteers. [published online ahead of print December 9, 2009]. Acad Emerg Med. 2010;17(1):9699. doi:10.1111/j.1553-2712.2009.00627.x.

58. Blehar DJ, Resop D, Chin B, Dayno M, Gaspari R. Inferior vena cava displacement during respirophasic ultrasound imaging. Crit Ultrasound J. 2012;4(1):18. doi:10.1186/2036-7902-4-18.

59. Funk DJ, Jacobsohn E, Kumar A. The role of venous return in critical illness and shock-part I: physiology. Crit Care Med. 2013;41(1):255-262. doi:10.1097/ CCM.0b013e3182772ab6.

60. Lansdorp B, Hofhuizen C, van Lavieren M, et al. Mechanical ventilation-induced intrathoracic pressure distribution and heart-lung interactions* Crit Care Med. 2014;42(9):1983-1990. doi:10.1097/ CCM.0000000000000345.

61. Barbier C, Loubières Y, Schmit C, et al. Respiratory changes in inferior vena cava diameter are helpful in predicting fluid responsiveness in ventilated septic patients. [published online ahead of print March 18, 2004]. Intensive Care Med. 2004;30(9):1740-1746. doi:10.1007/s00134-004-2259-8.

62. Machare-Delgado E, Decaro M, Marik PE. Inferior vena cava variation compared to pulse contour analysis as predictors of fluid responsiveness: a prospective cohort study. J Intensive Care Med. 2011;26(2):116-124. doi:10.1177/0885066610384192.

63. Corl K, Napoli AM, Gardiner F. Bedside sonographic measurement of the inferior vena cava caval index is a poor predictor of fluid responsiveness in emergency department patients. [published online 
ahead of print September 7, 2012]. Emerg Med Australas. 2012;24(5):534-539. doi:10.1111/j.17426723.2012.01596.x.

64. Lanspa MJ, Grissom CK, Hirshberg EL, Jones JP, Brown SM. Applying dynamic parameters to predict hemodynamic response to volume expansion in spontaneously breathing patients with septic shock. Shock. 2013;39(2):155-160. doi:10.1097/ SHK.0b013e31827f1c6a.

65. Muller L, Bobbia X, Toumi M, et al. Respiratory variations of inferior vena cava diameter to predict fluid responsiveness in spontaneously breathing patients with acute circulatory failure: need for a cautious use. Crit Care. 2012;16(5):R188. doi:10.1186/ cc11672.

66. de Witt B, Joshi R, Meislin H, Mosier JM. Optimizing oxygen delivery in the critically ill: assessment of volume responsiveness in the septic patient. [published online ahead of print August 1, 2014] J Emerg Med. 2014;47(5):608-615. doi:10.1016/j. jemermed.2014.06.015.

67. Monnet X, Rienzo M, Osman D, et al. Esophageal Doppler monitoring predicts fluid responsiveness in critically ill ventilated patients. [published online ahead of print July 30, 2005]. Intensive Care Med. 2005;31(9):1195-1201. doi:10.1007/s00134-0052731-0.

68. Slama M, Masson H, Teboul JL, et al. Monitoring of respiratory variations of aortic blood flow velocity using esophageal Doppler. [published online ahead of print March 5, 2004]. Intensive Care Med. 2004;30(6):1182-1187. doi:10.1007/s00134-0042190-z.

69. Feissel M, Michard F, Mangin I, Ruyer O, Faller JP, Teboul JL. Respiratory changes in aortic blood velocity as an indicator of fluid responsiveness in ventilated patients with septic shock. Chest. 2001;119(3):867-873.

70. Durand P, Chevret L, Essouri S, Haas V, Devictor D. Respiratory variations in aortic blood flow predict fluid responsiveness in ventilated children. [published online ahead of print February 8, 2008]. Intensive Care Med. 2008;34(5):888-894. doi:10.1007/ s00134-008-1021-z.

71. Lewis JF, Kuo LC, Nelson JG, Limacher MC, Quinones MA. Pulsed Doppler echocardiographic determination of stroke volume and cardiac output: clinical validation of two new methods using the apical window. Circulation. 1984;70(3):425-431.

72. Muller L, Toumi M, Bousquet PJ, et al. An increase in aortic blood flow after an infusion of $100 \mathrm{ml}$ colloid over 1 minute can predict fluid responsiveness: the mini-fluid challenge study. Anesthesiology. 2011;115(3):541-547. doi:10.1097/ ALN.0b013e318229a500.

73. Lamia B, Ochagavia A, Monnet X, Chemla D, Richard C, Teboul JL. Echocardiographic prediction of volume responsiveness in critically ill patients with spontaneously breathing activity. [published online ahead of print May 17, 2007]. Intensive Care Med. 2007;33(7):1125-1132. doi:10.1007/s00134-007-0646-7.

74. Maizel J, Airapetian N, Lorne E, Tribouilloy C, Massy Z, Slama M. Diagnosis of central hypovolemia by using passive leg raising. [published online ahead of print May 17, 2007]. Intensive Care Med. 2007;33(7):1133-1138. doi:10.1007/s00134-007-0642-y.

75. Monge García MI, Gil Cano A, Díaz Monrové JC. Brachial artery peak velocity variation to predict fluid responsiveness in mechanically ventilated patients. [published online ahead of print September 3, 2009]. Crit Care. 2009;13(5):R142. doi:10.1186/cc8027.

76. Blehar DJ, Glazier S, Gaspari RJ. Correlation of corrected flow time in the carotid artery with changes in intravascular volume status. [published online ahead of print April 2, 2014]. J Crit Care. 2014;29(4):486488. doi:10.1016/j.jcrc.2014.03.025.

77. Mackenzie DC, Khan NA, Blehar D, et al. Carotid Flow Time Changes With Volume Status in Acute Blood Loss. [published online ahead of print May 21, 2005]. Ann Emerg Med. 2015;66(3):277-282.e1. doi:10.1016/j.annemergmed.2015.04.014.

78. Stolz LA, Mosier JM, Gross AM, Douglas MJ, Blaivas M, Adhikari S. Can emergency physicians perform common carotid Doppler flow measurements to assess volume responsiveness? [published online ahead of print February 26, 2015]. West J Emerg Med. 2015;16(2):255-259. doi:10.5811/ westjem.2015.1.24301.

79. Marik PE, Levitov A, Young A, Andrews L. The use of bioreactance and carotid Doppler to determine volume responsiveness and blood flow redistribution following passive leg raising in hemodynamically unstable patients. Chest. 2013;143(2):364-370. doi:10.1378/chest.12-1274. 